\title{
Demonstration of the healthy worker survivor effect in a cohort of workers in the construction industry
}

\author{
U Siebert, D Rothenbacher, U Daniel, H Brenner
}

\begin{abstract}
Objectives-To assess the potential of a healthy worker survivor effect due to differential occupational mobility in a cohort of construction workers.

Methods-A cohort of 10809 male employees in the German construction industry aged 15-64 years was followed up for occupational mobility, early retirement due to permanent disability, and total mortality from 1986 to 1994 . Using the Cox's proportional hazards model of relative rates (RRs) with $95 \%$ confidence intervals (95\% CIs) of occupational mobility, early retirement and total mortality were estimated according to medical diagnoses at baseline after adjustment for various covariates.
\end{abstract}

Results-During follow up, 2472 subjects changed employment, 359 employees were granted a disability pension for health reasons and 188 subjects died. A wide range of chronic diseases was associated with increased rates of early retirement and total mortality but not occupational mobility. However, a healthy worker survivor effect was identified related to disorders of the back and spine (ninth revision of the international classification of diseases, ICD-9, code 720-4), a common predictor of both occupational mobility (RR $1.17,95 \% \mathrm{CI} 1.04$ to 1.32 ) and early retirement (RR $1.50,95 \%$ CI 1.20 to 1.88 ). In total, there were about as many events of occupational changes $(n=41)$ as events of early retirement due to permanent disability $(n=39)$ significantly attributable to disorders of the back and spine. Differential occupational mobility preceded differential early retirement due to permanent disability by more than one decade.

Conclusions-These findings show the need to consider a healthy worker survivor effect due to occupational mobility in occupational epidemiological research. Furthermore these results underline the necessity of further health promotion targeting work related conditions in the construction industry.

(Occup Environ Med 2001;58:774-779)

Keywords: healthy worker survivor effect; construction workers; occupational mobility; early retirement

U Siebert, Harvard Center for Risk Analysis, Harvard School of Public Health, 718 Huntington Avenue, Boston, MA 02115, USA

email:

sieb@1rz.uni-muenchen.de

Accepted 12 July 2001

In the German construction industry, almost two thirds of workers (63\%) retire due to permanent disability, whereas in the general workforce permanent disability accounts for $44 \%$ of retirement. ${ }^{1}$ Most cases of early retirement are due to chronic disorders that are symptomatic long before early retirement. Disorders of the musculoskeletal system are the predominant causes of disability among construction workers. ${ }^{2-5}$ Multiple risk factors of permanent disability have been identified, including preexisting diseases, individual predisposition, socioeconomic determinants, individual lifestyle, and working conditions. ${ }^{6-10}$

Although early retirement due to permanent disability is an important end point that causes increasing social and economic problems in industrialised countries, it reflects only a late stage of overall impairment. Despite improvements in working conditions in the construction industry over the past few decades, ${ }^{11}$ adverse effects resulting from heavy lifting and carrying, static work, climatic factors, noise, dust, and stress still impose heavy burdens ${ }^{12-17}$ that force construction workers to change their job before disability forces them into early retirement. ${ }^{18-20}$

Health related occupational mobility-that is, change of occupation - results in an ongoing differential selection process during the follow up of a working cohort and is referred to as the healthy worker survivor effect. ${ }^{2122}$ This is one of the key components of the healthy worker effect, ${ }^{23-26}$ along with the selective employment of healthy workers from the source population (healthy hire effect) and the decline in health with time since hire (time since hire effect).

Some experts have argued that epidemiological studies of early retirement due to permanent disability and total mortality that do not consider the selection process resulting from occupational mobility may underestimate the true risk of impaired health in the construction industry and other physically strenuous occupations. ${ }^{27-30}$ In analytical epidemiological studies, the healthy worker survivor effect generally attenuates adverse effects of the exposure under investigation. ${ }^{22}$

To our knowledge, there are no empirical data on the healthy worker survivor effect resulting from occupational mobility in construction workers. In this paper, we assess the potential of a healthy worker survivor effect due to differential occupational mobility in construction workers in a large cohort study, which was conducted to identify clinical predictors of early retirement due to permanent disability and total mortality. ${ }^{29}$

Subjects and methods
STUDY DESIGN AND STUDY POPULATION

In Germany, all employees of the construction industry are periodically invited to occupational health examinations by the occupational 
health service of the Workmen's Compensation Board for Construction Workers. In Germany, such occupational health examinations are based on legislation concerning health and safety at work "Arbeitssicherheitsgesetz". Although it is the employer's duty to provide employees with medical surveillance, the examinations are voluntary for the employees. A cohort study was conducted among construction workers who underwent occupational health examinations in one of six occupational health centres of the Workmen's Compensation Board for Construction Workers in Wuerttemberg, a federal state in the south of Germany.

In the baseline investigation, from August 1986 to December 1988, 78\% of invited employees participated in the examinations. This study comprises 10809 male employees aged 15-64 years who belonged to one of the following occupational groups: plumbers, carpenters, painters or varnishers, plasterers, bricklayers, and unskilled workers, as well as a group of white collar employees consisting of office employees, engineers, and architects.

DATA COLLECTION

The baseline health examination included working history, occupational and medical history, a physical examination, an audiogram, a visual acuity test, a pulmonary function test, and a blood and serum analysis. If necessary, an electrocardiogram and a chest radiogram were performed. The examinations were conducted by experienced occupational physicians of the medical health service of the Workmen's Compensation Board for Construction Workers and were documented according to a standardised protocol. Diagnoses of all prevalent diseases were listed by the physicians and coded according to the ninth revision of the international classification of diseases (ICD-9) by trained medical registrars.

Active follow up to assess employment and life status involved contacting employers and employees or their relatives between October 1992 and July 1994. Information on life status was compiled by the German system of registration offices and information on employment was complied by the worker's pension fund.

OUTCOME VARIABLES AND ASSESSMENT OF MORBIDITY

Three outcome variables were defined in the analyses of follow up data: occupational mobility, early retirement due to permanent disability (worker granted a disability pension), and total mortality. The beginning of the follow up period was defined as the date of the baseline health examination for each subject. The time of occupational change was defined as the time when the employee migrated from the employer at baseline to another employer. Changes between fields of activity within a company were not considered as occupational change. Subjects who became unemployed or ended employment for other reasons (self employment, continued education, professional development, military service) were considered as censored in the analysis of occupational mobility at the end of the employment period-that is, subjects' actual observation time until the end of employment was considered as time at risk for occupational mobility. For subjects with incomplete information, observations were censored at the time of last known information.

We assessed the occurrence of each of the three different outcomes according to the presence of the following medical diagnoses at baseline: obesity (ICD-9, code 278), disorders of lipid metabolism (ICD-9, code 272), ischaemic heart disease (ICD-9, code 410-414), hypertension (ICD-9, code 401), asthma (ICD-9, code 493), chronic bronchitis (ICD-9, code 491), chronic obstructive lung diseases (ICD-9, code 490-496), liver diseases (ICD-9, code 571-573, 790.4), disorders of the back and spine (ICD-9, code 720-724), arthropathies (ICD-9, code 710-719), skin diseases (ICD-9, code 690-692), and gout (ICD-9, code 274).

\section{STATISTICAL ANALYSIS}

Baseline characteristics, including prevalence at baseline examination of all medical diagnoses, response rates, mean follow up time, and crude incidences were assessed for all end points.

To assess the existence of a healthy worker survivor effect, further statistical analyses were performed in three steps. Firstly, associations between clinical predictors and all outcome variables were examined. Secondly, the predictors of occupational mobility were compared with the predictors of early retirement due to permanent disability and total mortality. Thirdly, clinical predictors that were simultaneously associated with (a) occupational mobility and $(b)$ early retirement or total mortality were candidates for causing a healthy worker survivor effect and they were examined further.

For each outcome, incidences were assessed for the complete study population. With univariate Cox's regression analyses ${ }^{31}$ for each outcome, crude rate ratios (RRs) with 95\% confidence intervals (95\% CIs) were calculated to compare the unadjusted outcome rate for employees with and without each medical diagnosis. Multivariable Cox's regression analyses were performed to adjust for the covariates age, nationality, profession, company size, and health related reduction in the capability to work at the time of the baseline examination. The proportional hazards assumption was evaluated graphically by the inspection of log-log survival curves. ${ }^{32}$ For all of the analysed models, the proportional hazards assumption was fulfilled.

Initially, likelihood ratio tests were performed to test for two factor interactions between the potential predictors and each of the covariates. ${ }^{33}$ To reduce the potential of randomly introduced interaction terms due to multiple testing, a significance level of 0.01 was used. None of these interactions was significant at this level, and therefore, no interaction terms were considered.

Medical diagnoses that were significantly $(p<0.05)$ associated with occupational mobility and one of the other outcome variables were considered as indicative of a potential healthy 
Table 1 Response rates, time of follow up, crude and age standardised incidences for occupational mobility, early retirement due to permanent disability, and total mortality in the follow up period

\begin{tabular}{llll}
\hline & $\begin{array}{l}\text { Occupational } \\
\text { mobility }\end{array}$ & $\begin{array}{l}\text { Early retirement } \\
\text { (pimanent } \\
\text { disability) }\end{array}$ & $\begin{array}{l}\text { Total } \\
\text { mortality }\end{array}$ \\
\hline $\begin{array}{l}\text { People examined at baseline (1986-8) (n) } \\
\text { People followed up (1992-4) }\end{array}$ & 10809 & 10809 & 10809 \\
Proportion of people followed up & 10668 & 9972 & 10429 \\
Total person-years & $98.7 \%$ & $92.3 \%$ & $96.5 \%$ \\
Mean duration of follow up (y) & 45785 & 45136 & 49585 \\
Events (n) & 4.3 & 4.5 & 4.8 \\
Incidence/100000 p-y (95\% CI) & 2427 & 359 & 188 \\
& 5301 & 795 & 379 \\
& $(5090$ to 5512) & $(713$ to 878$)$ & (325 to 433) \\
\hline
\end{tabular}

worker survivor effect. For employees with these diagnoses, the observed numbers of events of occupational mobility and numbers of events of occupational mobility that would have been expected in the absence of these diagnoses were calculated by 5 year age groups and compared with the corresponding number of events of early retirement due to permanent disability or total mortality. All statistical calculations were performed with the statistical software package SAS. ${ }^{34}$

\section{Results}

CHARACTERISTICS OF SUBJECTS AT BASELINE

EXAMINATIONS

The 10809 employees who underwent the baseline examinations had a mean (SD) age of 37.2 (13.2) years. Their mean cumulative duration of employment in the construction industry was 16.3 years. In this cohort, $78 \%$ of employees were of German nationality, $12 \%$ worked as plumbers, $13 \%$ as carpenters, $14 \%$ as painters or varnishers, $11 \%$ as plasterers, $31 \%$ as bricklayers, $14 \%$ as unskilled workers, and $4 \%$ as white collar employees.

The most frequent medical diagnoses at baseline examination were disorders of lipid metabolism, with a prevalence of $22.4 \%$ (95\% CI $21.6 \%$ to $23.2 \%$ ). This was followed by obesity $20.5 \%$ (95\% CI $19.7 \%$ to $21.3 \%$ ), disorders of the back and spine $16.3 \%$ (95\% CI $15.6 \%$ to $17.0 \%$ ), hypertension $14.7 \%$ (95\% CI $14.1 \%$ to $15.4 \%$ ), gout $12.5 \%$ (95\% CI $11.9-13.2 \%$ ), liver diseases $12.1 \%$ (95\% CI $11.5 \%$ to $12.7 \%$ ), arthropathies $7.4 \%$ (95\% CI $6.9 \%$ to $7.9 \%$ ), chronic obstructive lung diseases $4.2 \%$ (95\% CI $3.8 \%$ to $4.6 \%$ ), skin diseases $4.1 \%$ (95\% CI $3.7 \%$ to $4.5 \%$ ), ischaemic heart disease $4.0 \%$ ( $95 \%$ CI $3.7 \%$ to $4.4 \%$ ), chronic bronchitis $3.3 \%$ (95\% CI $2.9 \%$ to $3.6 \%$ ), and asthma $0.7 \%$ (95\% CI $0.5 \%$ to $0.8 \%$ ).

Follow up was ascertained for $98.7 \%$ of the employees for occupational mobility, for $92.3 \%$ for early retirement due to permanent disability, and for $96.5 \%$ for total mortality. Response rates, time of follow up, number of events, and incidences of occupational mobility, early retirement due to permanent disability, and total mortality are shown in table 1 . The mean follow up time was 4.3 years for occupational mobility, 4.5 years for early retirement due to permanent disability, and 4.8 years for total mortality. Over the follow up period, 2472 subjects changed employment, 359 employees were granted a disability pension due to health related reasons, and 188 subjects died. Occupational mobility was

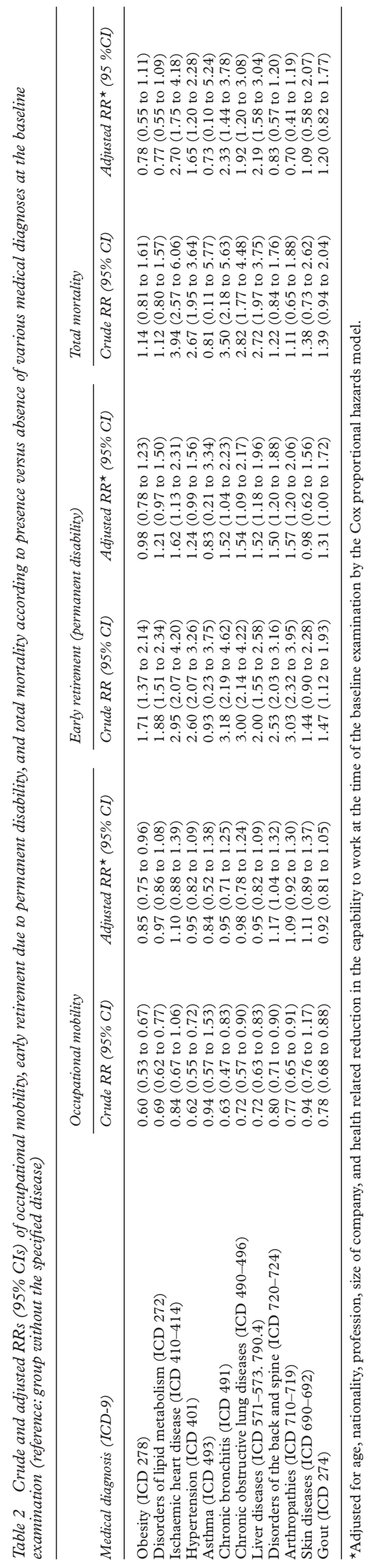


Table 3 Medical diagnoses as predictors of occupational mobility, early retirement due to permanent disability, and total mortality

\begin{tabular}{llll}
\hline Medical diagnosis & $\begin{array}{l}\text { Occupational } \\
\text { mobility }\end{array}$ & $\begin{array}{l}\text { Early retirement } \\
\text { (permanent } \\
\text { disability) }\end{array}$ & Total mortality \\
\hline Obesity & $\downarrow$ & - & - \\
Disorders of lipid metabolism & - & - & - \\
Ischaemic heart disease & - & - & $\uparrow$ \\
Hypertension & - & - & - \\
Asthma & - & $\uparrow$ & $\uparrow$ \\
Chronic bronchitis & - & $\uparrow$ & $\uparrow$ \\
Chronic obstructive lung diseases & - & $\uparrow$ & - \\
Liver diseases & - & $\uparrow$ & - \\
Disorders of the back and spine & $\uparrow$ & - & - \\
Arthropathies & - & - & - \\
Skin diseases & - & - & $\uparrow$ \\
Gout & & & $\uparrow$ \\
\hline
\end{tabular}

$\downarrow$ Reduced risk $(\mathrm{p} \leqslant 0.05)$; $\uparrow$ increased risk $(\mathrm{p} \leqslant 0.05)$; - no significant association $(\mathrm{p}>0.05)$.

high, with $40.1 \%$ of the subjects leaving their work during follow up; this was more common in younger employees (age $<40$ years, $45.6 \%$ ) than older ones (age $\geqslant 40$ years, $33.7 \%$ ). Younger employees left their baseline employers primarily to migrate to other companies $(64.0 \%)$. Older employees also migrated to other companies $(29.6 \%)$, but a significant number retired early due to permanent disability $(19.0 \%)$ and to old age $(13.9 \%)$.

Table 2 shows the crude and adjusted RRs and $95 \%$ CIs for each of the three outcomes, comparing employees with and without the listed medical diagnoses at the baseline examination.

OCCUPATIONAL MOBILITY

For each diagnosis, the univariate analyses of occupational mobility resulted in crude RRs below the null value, indicating a reduced occupational mobility among workers with disease diagnoses (table 2). However, only obesity was significantly associated with a lower occupational mobility rate after adjustment for age, nationality, profession, company size, and health related reduction in the capability to work at the time of the baseline examination (RR 0.85, 95\% CI 0.75 to 0.96 ). After adjustment, employees with disorders of the back and spine had a 1.17fold rate (95\% CI 1.04 to 1.32 ) of occupational change compared with employees without this diagnosis. Additional calculations for occupational mobility showed that the change in estimate from the crude to the adjusted RR was mainly due to the control of age.

\section{EARLY RETIREMENT DUE TO PERMANENT} DISABILITY

In the univariate analysis, the risk of early retirement due to permanent disability was significantly associated with all diagnoses except asthma and skin disease (table 2). Adjustment resulted in lower RRs, which were significantly greater than 1.0 for ischaemic heart disease (RR 1.62, 95\% CI 1.13 to 2.31 ), chronic bronchitis (RR 1.52, 95\% CI 1.04 to 2.23), chronic obstructive lung diseases (RR 1.54, 95\% CI 1.09 to 2.17 ), liver diseases (RR $1.52,95 \%$ CI 1.18 to 1.96$)$, disorders of the back and spine (RR $1.50,95 \%$ CI 1.20 to 1.88 ), and arthropathies (RR $1.57,95 \%$ CI 1.20 to 2.06 ).

\section{TOTAL MORTALITY}

For total mortality, death rates were significantly increased for ischaemic heart disease (RR $2.70,95 \%$ CI 1.75 to 4.18 ), hypertension (RR $1.65,95 \%$ CI 1.20 to 2.28 ), chronic bronchitis (RR 2.33, 95\% CI 1.44 to 3.78), chronic obstructive lung diseases (RR 1.92, 95\% CI 1.20 to 3.08), and liver diseases (RR 2.19, 95\% CI 1.58 to 3.04 ) after adjustment for the covariates (table 2).

HEALTHY WORKER SURVIVOR EFFECT

Table 3 shows the pattern of associations between the medical diagnoses and the three outcomes. The only diagnosis related to occupational mobility and early retirement due to permanent disability was disorders of the back and spine; no disease is related to both occupational mobility and total mortality. Obesity was inversely associated with occupational mobility, but had no significant association with the other outcomes. Thus, any assessment of the relation between disorders of the back and spine and early retirement due to permanent disability should consider the possibility of a healthy worker survivor effect due to differential occupational mobility. To confirm and

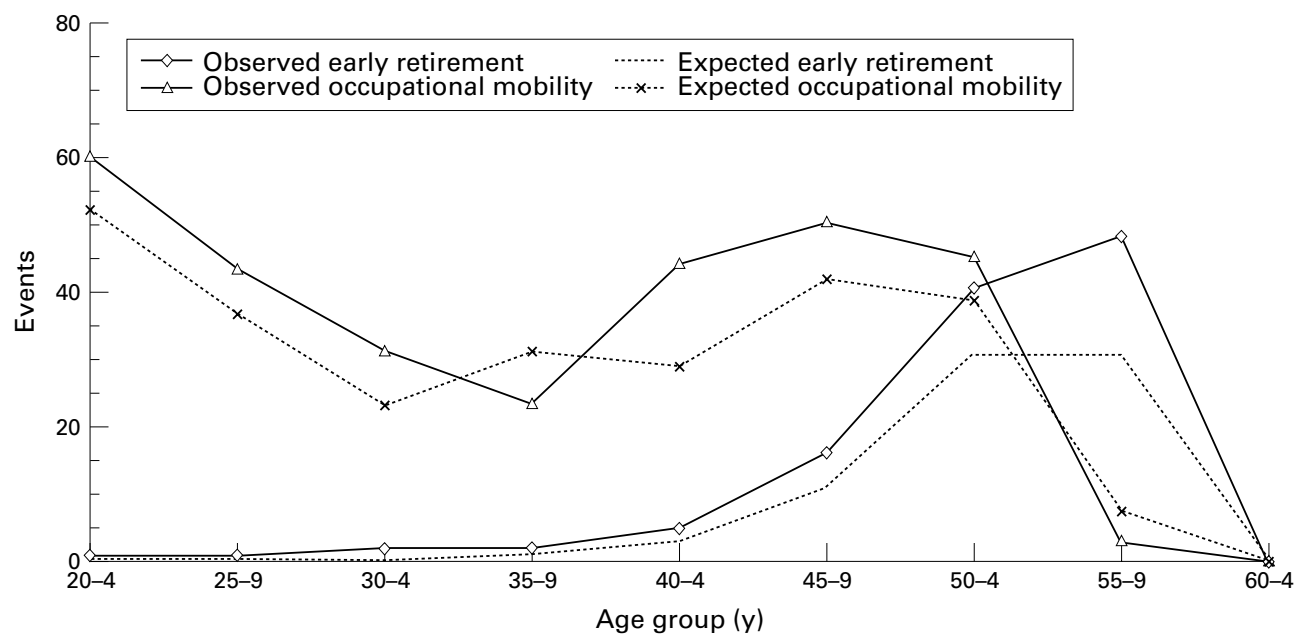

Figure 1 Occupational mobility and early retirement due to permanent disability from disorders of the back and spine. Observed events in employees with disorders of the back and spine and expected events without disorders of the back and spine by 5 year age groups. 
illustrate the presence of a healthy worker survivor effect, it is necessary to consider the time course of the events under study.

Figure 1 presents the observed number of events of occupational mobility and early retirement due to permanent disability for employees with disorders of the back and spine by 5 year age groups. They are compared with the events that would have been expected without disorders of the back and spine. For each outcome, the area between the curves for the expected and observed values represents the events that are significantly attributable to disorders of the back and spine. Although there was some differential occupational mobility by disorders of the back and spine in the 20-30 year age groups, it was most pronounced in ages 40-50. Most early retirements due to permanent disability that were significantly attributable to disorders of the back and spine were found in ages 50-60. Thus, differential occupational mobility preceded differential early retirement due to permanent disability by at least 1 decade. This time sequence of occupational mobility and early retirement due to permanent disability, both related to disorders of the back and spine, suggests the presence of a healthy worker survivor effect. In total, there were about as many events of occupational change $(n=41)$ as events of early retirement due to permanent disability $(n=39)$ that were significantly attributable to disorders of the back and spine.

\section{Discussion}

The present study investigated the role of various chronic diseases in occupational mobility, early retirement due to permanent disability, and total mortality in a regional cohort of employees of the German construction industry. We also considered the potential of a healthy worker survivor effect due to differential occupational mobility.

After adjustment for various factors, several chronic diseases of for example, the cardiovascular system or the respiratory tract, were found to be associated with one or more of the three study end points. However, the pattern of associated diseases was different for each of these outcomes. A potential healthy worker survivor effect due to differential occupational mobility was identified for the relation between disorders of the back and spine and early retirement due to permanent disability.

The discrepancy between crude and adjusted results was mainly due to confounding by age. In particular, high age was a common cause for morbidity as well as the risk of early retirement due to permanent disability and total mortality. This led to an overestimation of disease effects in the crude analysis of these end points. By contrast, younger workers were more likely to migrate to another employer. Thus, the disease effects on occupational mobility were underestimated in the crude analysis. For several diseases, the crude RR of occupational mobility was below 1.0 whereas the adjusted RR was above 1.0. Some authors refer to this type of bias as switchover bias. ${ }^{25}$

As predictors of total mortality and early retirement due to permanent disability, severe diseases of the heart, lung, and liver with known potential for disability and death were identified after adjustment. Additionally, disorders of the back and spine as well as arthropathies were found to have a positive association with early retirement due to permanent disability. Arthropathies are more common in certain occupational groups, including construction workers. Musculoskeletal disorders occur in all age groups and-despite their low mortality-lead to substantial disability and reduction of quality of life. Because of their individual, medical, and economic consequences, they are a major topic of the current discussion about public health.

This analysis of occupational mobility indicated that migration from one employer to another during the follow up period was partially dependent on health at baseline. Employees without disorders of the back and spine at the baseline examination were more likely to "survive" in employment. As early retirement due to permanent disability was more likely in subjects with disorders of the back and spine, the selection of healthier workers during the follow up period led to a reduced risk of early retirement due to permanent disability for the remaining population. By contrast with the selection process at the time of hiring, the effect described is related to the selection process during employment, and therefore classified as a healthy worker survivor effect.

When rates of early retirement due to permanent disability are used to measure health related, long term consequences of diseases, the healthy worker survivor effect leads to an underestimation of these consequences, because morbidity in migrated workers is not considered. In the present investigation, there were as many events of occupational change as there were events of early retirement due to permanent disability related to disorders of the back and spine.

Although RRs are the measures most commonly used in the analysis of occupational cohort studies, from a public health perspective the presentation of absolute numbers and attributable events may sometimes be more informative, and thus were part of this analysis. The increased risk of early retirement due to permanent disability in younger employees with disorders of the back and spine did not contribute substantially to the total number of early retirements due to permanent disability, because the baseline rates were low for employees under 45 (fig 1). By contrast, overall and disease related occupational mobility is a continuous process that leads to a remarkable number of job changes before the age of 45 . Prevention policy should consider this specific age pattern.

One limitation of this study is the low specificity of occupational mobility as a health related outcome due to limited availability of information about the causes of job changes. Furthermore, the change from one employer to another must be regarded as a proxy outcome for change of activity. Surveys in the German construction industry ${ }^{35}$ suggest that only a small proportion of workers $(5 \%)$ remain in the 
construction industry after changing employment, whereas $68 \%$ change their occupation and $22 \%$ continue their education. As already noted, those who left the construction industry were censored in our study. About $25 \%$ of job changes were induced by health problems; however, health impairments persisted in every second worker after migration. ${ }^{35}$ On the other hand, a shift to less strenuous work was reported for workers who remained employed and did not switch employers during the follow up period. With increasing age, these workers tended to perform less heavy manual handling of materials, and changes from construction work to repair work ${ }^{28}$ or white collar work ${ }^{36}$ were more frequent. Because these changes in activity were not reflected by employment status, masked selective survival may exist even in studies that consider occupational mobility. We refer to this phenomenon, which leads to an underestimation of the effects of exposures under investigation, as the "residual healthy worker survivor effect".

The basis of this investigation were data collected during routinely performed occupational health examinations conducted by many occupational health physicians. Despite standardised documentation, some subjectivity may remain in the diagnosis. To minimise this potential source of bias, we worked only with the three digit ICD code and summarised diseases in related groups. However, the physicians were not aware of a specific research question and thus potential misclassification was likely to be non-differential with respect to the outcomes.

The strengths of the present study consist of the large sample size of the cohort, which comprises about a tenth of all employees in the construction industry working in the study region, as well as simultaneous assessment of occupational mobility and other end points, which allowed investigation of the potential for a healthy worker survivor effect in a systematic manner.

\section{Conclusions}

The results of this study indicate the need to consider a potential healthy worker survivor effect in the evaluation of work related risk factors for early retirement due to permanent disability. Therefore, future analyses should include consideration of occupational mobility to avoid underestimation of the effect of preexisting disease on employees health. Although this analysis was restricted to employees in the construction industry, this approach could also be of relevance in other areas of occupational epidemiological research.

This study was partly supported by the Association of the Workmen's Compensation Board for Construction Workers, Germany.

1 VDR Statistik Rentenzugang 1991. Vol 99. Frankfurt: Verband Deutscher Rentenversicherungsträger, 1992.

2 Damlund M, Goth S, Hasle P, et al. Low-back pain and early retirement among Danish semiskilled construction workers. Scand $\mathcal{F}$ Work Environ Health 1982;8(suppl 1):100-4.

3 Drexel G, Francks P, Plinske W, et al. BK-Dok 90. Dokumentation des Berufskrankheiten-Geschehens in der Bundesrepublik Deutschland. Sankt Augustin: Hauptverband der gewerblichen Berufsgenossenschaften, 1992

4 Garg A, Moore JS. Epidemiology of low-back pain in industry. Occup Med 1992;7:593-608.
5 Rothenbacher D, Brenner H, Arndt V, et al. Disorders of the back and spine in construction workers. Prevalence and back and spine in construction workers. Prevalence

prognostic value for disability. Spine 1997;22:1481-6.
6 Wasilewski R, Faßmann H, Kentner M, et al. Frühinvalidisierung: Ergebnisse einer Untersuchung in BadenWürttemberg. Stuttgart: Ministerium für Arbeit, Gesundheit und Sozialordnung Baden-Württemberg, 1984

7 Rothenbacher D, Arndt V, Fraisse E, et al. Chronic respiratory disease morbidity in construction workers: patterns and prognostic significance for permanent disability and overall mortality. Eur Respir F 1997;10:1093-9.

8 Rothenbacher D, Arndt V, Fraisse E, et al. Early retirement due to permanent disability in relation to smoking in workers of the construction industry. $\mathcal{F}$ Occup Environ Med 1998;40:63-8.

9 Frank JW, Kerr MS, Brooker AS, et al. Disability resulting from occupational low back pain. Part I: What do we know about primary prevention? A review of the scientific evidence on prevention before disability begins. Spine 1996;21:2908-17.

10 Frank JW, Brooker AS, DeMaio SE, et al. Disability resulting from occupational low back pain. Part II: What do we know about secondary prevention? A review of the scientific evidence on prevention after disability begins. Spine 1996;21:2918-29.

11 Garg A, Moore JS. Prevention strategies and the low back in industry. Occup Med 1992;7:629-40

2 Holmström EB, Lindell J, Moritz U. Low back and neck/shoulder pain in construction workers: occupational workload and psychosocial risk factors. Part 1: Relationship to low back pain. Spine 1992;17:663-71.

13 Holmström EB, Lindell J, Moritz U. Low back and neck/shoulder pain in construction workers: occupational workload and psychosocial risk factors. Part 2: Relationship to neck and shoulder pain. Spine 1992;17:672-7.

14 Stenlund B, Goldie I, Hagberg M, et al. Radiographic osteoarthrosis in the acromioclavicular joint resulting from manual work or exposure to vibration. Br f Ind Med 1992; 49:588-93.

15 Stenlund B, Goldie I, Hagberg M, et al. Shoulder tendinitis and its relation to heavy manual work and exposure to vibration. Scand $\mathcal{F}$ Work Environ Health 1993;19:43-9.

16 Hunting KL, Welch LS. Occupational exposure to dust and lung disease among sheet metal workers. $B r \quad \mathcal{F}$ Ind $M e d$ 1993;50:432-42.

17 Latza U, Karmaus W, Stürmer T, et al. Cohort study of occupational risk factors of low back pain in construction workers. Occup Environ Med 2000;57:28-34.

18 Bundesministerium für Bildung und Wissenschaft. Berufsbildungsbericht 1994. Grundlagen und Perspektiven für Bildung und Wissenschaft. Vol 40. Bonn: Bundesministerium für Bildung und Wissenschaft, 1994

19 VDR Statistik Rehabilitationsmaßnahmen 1990. Vol 97. Frankfurt: Verband Deutscher Rentenversicherungsträger, 1991.

20 VDR Statistik Rentenzugang 1990. Vol 96. Frankfurt: Verband Deutscher Rentenversicherungsträger, 1991.

21 Robins J. A new approach to causal inference in mortality studies with a sustained exposure period: application to control of the healthy worker survivor effect. Mathematical Modeling 1986;7:1393-512.

22 Arrighi HM, Hertz-Picciotto I. The evolving concept of the healthy worker survivor effect. Epidemiology 1994;5:18996.

23 Fox AJ, Collier PF. Low mortality rates in industrial cohort studies due to selection for work and survival in the industry. Br F Prev Soc Med 1976;30:225-30.

24 Hennekens C, Buring JE. Epidemiology in medicine. Boston: Little Brown, 1987.

25 Kleinbaum DG, Kupper LL, Morgenstern H. Epidemiologic research. New York: Van Nostrand Reinhold, 1982.

26 Checkoway H, Pearce N, Crawford-Brown DJ. Research methods in occupational epidemiology: monographs in epidemimethods in occupational epidemiology: monographs in epidemiPress, 1989.

27 Delzell E, Monson RR. Mortality among rubber workers: IV. General mortality patterns. F Occup Med 1981;23:850-6.

28 Karmaus W, Patjens S. Wie gesundheitsgefährdend ist die Bauarbeit? Arbeitsbedingtheit von Erkrankungen des Stütz- und Bewegungsapparates bei Maurern und Bauarbeitern. WSI Mitteilungen 1985;4:200-7.

29 Arndt V, Rothenbacher D, Brenner H, et al. Older workers in the construction industry: results of a routine health examination and a 5 year follow up. Occup Environ Med 1996;53:686-91.

30 Sorock GS, Courtney TK. Epidemiologic concerns for ergonomists: illustrations from the musculoskeletal disorder literature. Ergonomics 1996;39:562-78.

31 Cox DR. Regression models and life tables. Fournal of the Royal Statistical Society B 1972;34:187-220.

32 Collett D. Modelling survival data in medical research. London: Chapman and Hall, 1994

33 Hosmer DW Jr, Lemeshow S. Applied survival analysis. New York: John Wiley, 1999.

34 SAS Institute. SAS Language: reference, 1 st ed. Cary, NC: SAS Institute, 1990.

35 Bundesministerium für Bildung und Wissenschaft. Berufsbildungsbericht 1986. Grundlagen und Perspektiven für Bildung und Wissenschaft. Vol 10. Bonn: Bundesministerium für Bildung und Wissenschaft, 1986.

36 Schlombach C, Schmidt S. Gesundheits- und Krankheitsentwicklung der Berliner Bauarbeiter im Spiegel der bis 1972 [Dissertation]. Berlin: University of Berlin, 1978. 